\title{
Issues in Planning a Placebo-Controlled Trial of Manual Methods: Results of a Pilot Study
}

\author{
CHERYL HAWK, D.C., Ph.D., ${ }^{1}$ CYNTHIA R. LONG, Ph.D. ${ }^{1}$ ROBERT REITER, M.D., ${ }^{2}$ \\ CHARLES S. DAVIS, Ph.D., ${ }^{3}$ JERRILYN A. CAMBRON, D.C., M.P.H., ${ }^{4}$ \\ and RONI EVANS, D.C., M.S. ${ }^{5}$
}

\begin{abstract}
Objective: There are fundamental differences between the administration of medications and the application of manual procedures, such as those used by chiropractors. The objective of this study was to gather preliminary information on how to address these differences in the design of a multisite, randomized placebo-controlled trial of chiropractic care for women with chronic pelvic pain (CPP).

Design: Pilot study for a multisite, randomized, placebo-controlled clinical trial.

Setting: Three chiropractic research clinics in the midwest United States.

Subjects: Thirty-nine (39) women with CPP of at least 6 months' duration, diagnosed by boardcertified gynecologists.

Interventions: The active intervention consisted of the chiropractic technique, lumbar spine flexion-distraction, combined with manual Trigger Point Therapy. The placebo intervention consisted of a sham chiropractic procedure performed with an instrument combined with effleurage (light massage).

Outcome measures: The primary outcome measure was the change in the Pain Disability Index (PDI) from baseline to the end of treatment (6 weeks), assessed by group and site. If the change score was in the same direction at all sites, the results were to be combined to estimate treatment effect size.

Results: Patient characteristics were similar to those of patients with CPP in other studies. Recruitment methods, particularly in respect to the eligibility criteria and screening protocols, would require modification in order to recruit an adequate sample for the planned randomized controlled trial. Clinicians followed standardized procedures with apparently minimal deviation, patients in both groups were satisfied with their care and blinding appeared to be successful. PDI change scores were not consistent across sites and so results were not combined and overall treatment effect sizes were not estimated.

Conclusions: The technical and personnel resources required to achieve adequate standardization of procedures at multiple sites may make a placebo-controlled trial unfeasible, given our current lack of knowledge about the active agent in manual chiropractic procedures.
\end{abstract}

\footnotetext{
${ }^{1}$ Palmer Center for Chiropractic Research, Davenport, IA.

${ }^{2}$ Promedica Health System, Toledo, $\mathrm{OH}$.

${ }^{3}$ University of Iowa College of Public Health, Department of Biostatistics, Iowa City, IA.

${ }^{4}$ National University of Health Sciences, Lombard, IL.

${ }^{5}$ Northwestern Health Sciences University, Bloomingdale, MN.
} 


\section{INTRODUCTION}

$\mathbf{T}$ he randomized clinical trial (RCT), most often placebo-controlled, has been considered the gold standard of clinical research. Therefore, complementary and alternative medicine (CAM) practices, including manual therapies, are expected to use this design to document efficacy (Kaptchuk, 1999; Vickers, 1996). Although a much-publicized systematic review of clinical trials called into question the validity of the use of placebos, it is important to note that this study concluded that placebos appeared to have some benefit in trials that used continuous subjective outcomes and treated pain, and that, in fact, use of placebo is only unwarranted "outside the setting of clinical trials" (Hrobjartsson and Goetzsche, 2001, p. 1594).

However, there are important differences between administering medications and applying manual CAM procedures. These raise problematic issues in the design and conduct of placebo-controlled RCTs for manual CAM procedures such as those used by chiropractors (Bolton, 1999; Hawk, 2000; Joyce, 1994).

One of these issues is the lack of a definitive, single active agent in chiropractic care. The reason for patients' improvement may not be the specific manual procedures but a psychophysical gestalt encompassing the entire clinical encounter (Coulehan, 1985; Oths, 1994). Another issue is the use of individualized procedures with nonstandardized delivery parameters. These lead to the third issue: it is difficult to be sure that the placebo treatment does not possess the same attributes as the active treatment, resulting in a misclassification error. This possibility has not, to date, been adequately addressed in RCTs of manual therapies (Balon et al., 1998; Bove and Nilsson, 1998; Hondras et al., 1999). Often the "placebo" in one CAM trial is an active agent in another (Bove and Nilsson, 1998; Field et al., 1996; Ironson et al., 1996; Maa et al., 1997).

A fourth issue, especially challenging in manual therapy RCTs, relates to blinding to treatment group assignment, which is important to minimize bias: it is impossible to blind clinicians administering the manual treatment and difficult to blind patients. In addition to these design issues common to trials of manual procedures, choice of appropriate eligibility criteria can be problematic when the study focuses on one of the chronic and ill-defined conditions for which patients frequently seek CAM care.

Most of these issues can be addressed by minimizing the variability of the manual procedures and clinical encounter, such as by conducting the trial at a single site with a single clinician and using strict eligibility criteria to maximize homogeneity of the patient sample. However, to investigate the effects of CAM care on conditions less common than, for example, low back pain, a single site will probably not yield a large enough sample to adequately power the study.

In order to gather preliminary information on how to address these issues to design a multisite trial of chiropractic care for women with chronic pelvic pain (CPP), we conducted a pilot study at three sites from 1999-2000. The rationale for conducting this pilot study was based partially on the results of a previous single-group study using one clinician, which had shown clinically important reductions in CPPrelated pain and disability (Hawk et al., 1997). This paper presents the results of the multisite pilot study.

\section{MATERIALS AND METHODS}

\section{Patients and clinic sites}

Study population and eligibility criteria. Because this was a pilot for a larger study, not an efficacy study, the targeted sample size of 20 patients at each of three sites was based on available resources for recruitment.

Inclusion criteria were:

1. Females ages $18-45$.

2. Diagnosis of CPP by each site's screening gynecologist. The gynecologic examination determined the presence of: (1) pelvic pain more than 6 months; (2) negative bimanual examination; (3) possible musculoskeletal etiology; (4) negative screening laboratory; (5) no indications for laparoscopy (if immediate laparoscopy was indicated to rule out 
remediable intrapelvic pathology, the patient was excluded).

3. Naive to chiropractic manipulation, defined for this study as not having received chiropractic care: (1) for the past year, and (2) for pelvic pain (by patient report).

Exclusion criteria were:

1. Pregnancy.

2. Menopause (cessation of menstruation less than 6 months).

3. Reproductive tract surgery within the past 6 months.

4. Presence of pathology or conditions requiring medical treatment and/or presenting contraindication to chiropractic treatment, as determined by the gynecologist.

5. Contraindications to manipulation, such as presence of fracture or certain structural abnormalities.

6. Absence of indications of musculoskeletal dysfunction, which include pain, tenderness, trigger points in the low back, abdominal, and pelvic musculature, and lack of mobility of lumbar and lumbosacral joints, as determined by the chiropractic clinician.

7. Litigation for a health-related claim (in process or pending).

8. Under treatment, medical or other, currently for any condition other than CPP, excluding counseling or psychotherapy.

Clinic sites. The three sites, in three midwestern states, were: (1) a chiropractic outpatient clinic in a large metropolitan area; (2) a chiropractic multidisciplinary outpatient clinic in a large metropolitan area; (3) a chiropractic college research clinic in a smaller metropolitan area.

\section{Human subjects}

Each site's Institutional Review Board approved the project. Informed consent forms were signed by all patients as described below. All records were maintained in secure files according to the sites' usual clinical protocols. For transmission of any clinical records with patient identifiers to the data coordinating center (DCC), a secure carrier was used. All other study data were sent via priority mail, because no patient identifiers were included.

\section{Recruitment, enrollment, and}

\section{treatment assignment}

Patients were recruited through local radio, newspapers, direct mail, and referral from other providers. These procedures have been described elsewhere (Byrd et al., 1999).

Women calling in response to the advertisements were asked to complete a telephone screening interview. Those eligible and willing to participate were scheduled for a clinic visit to complete a questionnaire and personal interview. Those remaining eligible met with staff to discuss the study, sign the informed consent and be examined by the chiropractor. Eligible women were scheduled with the gynecologist for verification of the diagnosis of CPP. Women who remained eligible were invited to enroll in the study.

Enrolled patients were randomly assigned to the active or control group at the first treatment session. The DCC made all treatment assignments using a predetermined restricted randomization scheme with random block sizes, generated separately for each site.

\section{Interventions}

In selecting the chiropractic technique for the active intervention, we took an evidence-based approach, choosing the technique with the best available published evidence for its utility for patients with CPP.

In developing the protocol for delivery of all manual procedures, in the absence of authoritative data for a threshold of biomechanical force below which a specific effect does not occur, we used consensus of the experienced clinicians and investigators. Before the study began, they identified an appropriate level of biomechanical force for each procedure. For the active procedures, this was based on usual and customary practice by experienced chiropractors. For the placebo intervention, this was based in part on feedback from volunteers and in part on clinical experience, with the goal of designing a placebo maneuver that produced the smallest possible treatment effect, because of our recognition that any manual procedure 
inevitably produces some type of physiologic response.

Active intervention. The primary chiropractic technique for delivering adjustments (the term used within the profession for the use of manual force resulting in correcting a subluxation, which is defined in chiropractic as an area of joint dysfunction) was lumbar spine flexiondistraction, a manual procedure commonly used in chiropractic practice. This technique was used rather than the most commonly used chiropractic technique because flexion-distraction is the only chiropractic technique reported in published literature as showing utility in CPP treatment (Browning, 1996, 1991, 1988, 1987; Polk, 1991; Hawk et al., 1997). The secondary technique was manual trigger point therapy to the low-back and pelvic area, another procedure commonly used by chiropractors, involving manual ischemic compression of muscles where localized regions of painful contracted tissue are palpated.

Placebo intervention. The placebo treatment consisted of a sham adjustment combined with effleurage (light massage). Because the consensus of the investigators and clinicians was that a sham procedure mimicking flexion-distraction would be difficult to perform without causing a significant treatment effect, sham adjustments were performed with a hand-held adjusting instrument set to deliver no pressure, and applied only to soft tissue adjacent to the spine.

Other aspects of the clinical encounter. In order to create similar expectations in both groups, treatment visit frequency and duration were standardized to 15 minutes per treatment visit and 14 treatment visits. Patient support by the clinician was also standardized and deviations were recorded.

\section{Standardization of protocols among sites}

A 2-day training session was conducted prior to recruitment to standardize procedures and protocols, and a Manual of Operating Procedures was provided. Throughout the study, site teams met regularly, with periodic intersite conference calls.
Standardization of intervention procedures. All clinicians had been certified in the chiropractic techniques and primary clinicians had at least 5 years experience.

At the training session, clinicians applied each manual procedure with student volunteers as patients, using a specially designed chiropractic table equipped with force-plates and a computerized real-time display to ensure replicability. The clinicians practiced the interventions until they were able to reproduce them consistently. However, this equipment was not available at all sites so could not be used throughout the study for reinforcement.

\section{Frequency and duration of treatment}

The treatment plan was based on common chiropractic practice, and consisted of 6 weeks of treatment with three visits a week for 2 weeks and twice a week for 4 weeks (total = 14) (Haldeman et al., 1992).

\section{Blinding}

Patients were not told their group assignment until the week 12 follow-up visit, after they were asked which group they believed they had been in and why. Blinding of the chiropractic clinician was not possible. The research assistant, blinded to patients' treatment group status, administered all outcome assessments.

\section{Patient assessment}

Outcome assessments were done at baseline (prior to contact with the clinician), week 3, and week 6. Follow-up assessments occurred at week 12 (prior to unblinding) and week 24 by mail. The primary outcome assessment point was at week 6 . Week 3 assessments were done to provide information in case patients dropped out prior to the week 6 visit.

The primary outcome analysis was comparison of the score for the Pain Disability Index (PDI) at baseline and after 6 weeks of treatment. We used the PDI because patient-reported symptoms of disability are more predictive of outcomes than diagnostic tests (Gronblad et al., 1993, 1994). The PDI, a seven-item patient questionnaire with a scoring range of $0-70$, assesses 
perception of chronic pain-related disability (Chibnall and Tait, 1994; Nordstrom et al., 1996; Tait et al., 1987, 1990). Although the PDI's clinical responsiveness has not yet been definitively described, it appears that six points represents a clinically important change (Nordstrom et al., 1996). The McGill Pain Questionnaire (MPQ) and the Visual Analogue Scale (VAS) for Pain were used for additional information (Melzack, 1983; Miller and Ferris, 1993; Wewers and Lowe, 1990).

Other instruments provided baseline information for purposes of comparison, including the Medical Outcomes Study 36-Item ShortForm Health Survey (SF-36) and the Beck Depression Inventory (BDI) (Beck et al., 1988; Ware et al., 1993).

Patients evaluated the doctor-patient interaction via a questionnaire about time spent, technical skills, communication and rapport.

\section{Patient compliance}

Patient compliance was assessed by adherence to the schedule and protocol. Noncompliance with the schedule was defined as missing more than one treatment visit within a 2-week interval. Noncompliance to the protocol was defined as concurrent use of excluded treatments. Patients were asked at each visit about such use.

\section{Data management}

One of the sites used a computer-assisted telephone interviewing system. All other data were collected on hard copy forms forwarded to the DCC where they were double-key-entry verified. The gynecologic screening form was transferred via fax. Data collection forms remained in a secure location at the DCC and electronic data in a password-protected $\mathrm{Mi}$ crosoft Access database on a secured network. Final data were exported to SAS where they were further managed to create the data set for analysis.

\section{Data analysis}

Recruitment, screening, and enrollment data were monitored throughout the study. Baseline data were described for each treatment group.
Outcome data were first described separately using medians and ranges for both treatment groups at each site. As specified in the original data analysis plan, the direction of the treatment effect for the primary outcome variable was assessed at each site; if these treatment effects were in the same direction, the data were combined across sites to provide point and interval estimates of the mean difference in the changes between the active and control treatment groups.

\section{RESULTS}

\section{Recruitment and enrollment}

As shown in Table 1, of 355 potential patients who contacted a site by phone, 202 were ineligible, 109 because of chiropractic experience within the last year. Of the 153 eligible callers, 83 reported for the onsite screening interview. Although none were found ineligible at the chiropractic screening examination, because of scheduling difficulties only 49 potential patients completed the gynecologic screening, with a mean waiting time for subsequently enrolled patients of 22 days (range, 2-49) for the gynecologic examination. Seven of these were determined ineligible by the gynecologist. However, 3 of the 7 were eligible by the study's gynecologic diagnostic criteria, but the site's gynecologist did not follow these criteria. A total of 39 patients were enrolled in the study (3 eligibles declined to participate). Of these 39, 20 were randomly assigned to the active treatment group and 19 to the placebo group; 36 patients completed the study $(7.6 \%$ attrition).

\section{Baseline patient characteristics}

As shown in Table 2, there were no striking differences at baseline between groups. Table 3 shows medication and food supplement use at baseline. The distributions were similar in the two groups. Nineteen (19) of 39 patients reported no prescription medication use and 12 no nonprescription medication use. Fourteen (14) patients reported no use of supplements or herbs, and none reported such use for CPP. 
Table 1. Summary of Recruitment and Enrollment

\begin{tabular}{|c|c|c|c|}
\hline \multirow[b]{2}{*}{ Phase of study } & \multicolumn{2}{|c|}{$\mathrm{n}$} & \multirow[b]{2}{*}{ Reasons for attrition between phases } \\
\hline & Presenting & $\begin{array}{l}\text { Dropouts/ } \\
\text { ineligible }\end{array}$ & \\
\hline $\begin{array}{l}\text { Telephone } \\
\text { screening } \\
\text { interview }\end{array}$ & 355 & 202 & $\begin{array}{l}\text { 109, chiropractic within last year } \\
60 \text {, other exclusion criteria } \\
\text { 33, did not complete screening interview }\end{array}$ \\
\hline $\begin{array}{l}\text { Eligible callers } \\
\text { from telephone } \\
\text { screening }\end{array}$ & 153 & 70 & $\begin{array}{l}\text { 52, no show } \\
17 \text {, not willing/interested } \\
1 \text {, low-back pain only, not CPP }\end{array}$ \\
\hline $\begin{array}{l}\text { In-person } \\
\text { screening } \\
\text { interview }\end{array}$ & 83 & 8 & $\begin{array}{l}\text { 2, refused possibility of placebo } \\
2 \text {, no shows } \\
\text { 2, cancelled } \\
1 \text {, refused male gynecologist } \\
1 \text {, refused informed consent }\end{array}$ \\
\hline $\begin{array}{l}\text { Chiropractic } \\
\text { examination }\end{array}$ & 75 & 26 & $\begin{array}{l}\text { 24, no shows } \\
1 \text {, withdrawal } \\
1 \text {, said "it took too long to get in to the } \\
\text { gynecologist" }\end{array}$ \\
\hline $\begin{array}{l}\text { Gynecologic } \\
\text { examination }^{\mathrm{b}}\end{array}$ & 49 & 7 & $\begin{array}{l}\text { 1, scarring in pelvis } \\
\text { 1, uterine fibroids } \\
\text { 1, previous pelvic pathology, phyisican ordered } \\
\text { laparoscopy } \\
\text { 1, gallbladder disease, not CPP } \\
\text { 1, dysmenorrhea, not CPP } \\
\text { 2, endometriosis with cyclic rather than acyclic } \\
\text { pain }\end{array}$ \\
\hline $\begin{array}{l}\text { Eligible for } \\
\text { study }\end{array}$ & 42 & 3 & $\begin{array}{l}1 \text {, no show } \\
2 \text {, work schedule did not accommodate }\end{array}$ \\
\hline Enrolled & 39 & 3 & $\begin{array}{l}\text { 1, did not like treatment (placebo group) } \\
1 \text {, no show (active) } \\
\text { 1, illness requiring hospitalization (active) }\end{array}$ \\
\hline Completed study & 36 & & \\
\hline
\end{tabular}

a"No show" indicates lost to follow-up; study personnel could not contact patient.

${ }^{b}$ Mean number of days between screening and gynecologist appointment for patients who completed gynecologic screening $=22($ range, $2-49)$

$\mathrm{CCP}$, chronic pelvic pain.

Assessment of the standardization of the intervention protocols

All clinicians documented treatment procedures and patient symptoms at each visit. Noted deviations in the prescribed treatment protocols are described below:

1. Use of one primary clinician (PC) per site to provide all chiropractic procedures at the 14 treatment visits with backup clinicians for emergencies only. There was some variation by site for use of primary clinician. At site 1, the PC, who had more than 20 years' experience and was one of the primary developers of the chiropractic protocol used, was the sole clin- ician for 10 of 18 patients. The backup clinician was a resident certified in the techniques. At site 2, both the primary and backup clinician were equally experienced and qualified (one with 10 and one with 12 years experience). Eleven (11) of 12 patients received care primarily from one clinician. At site 3, the PC, with approximately 5 years experience, provided all care for 6 of 9 patients. The backup clinicians were both residents certified in the techniques.

2. Application of active treatment procedures. Active treatment procedures were delivered as prescribed except that at site 1, trigger point therapy was not performed for 5 of 10 patients, and an additional procedure not in- 
Table 2. Baseline Characteristics, Symptoms and Health History of Patients (by patient Report)

\begin{tabular}{|c|c|c|c|}
\hline & Placebo $(\mathrm{n}=19)$ & $\begin{array}{c}\text { Active } \\
\text { group }(\mathrm{n}=20)\end{array}$ & Total $(\mathrm{n}=39)$ \\
\hline Age-mean (SD) & 33.7 (7.6) & 34.7 (7.6) & $34.2(7.5)$ \\
\hline Race-white & 18 & 14 & 32 \\
\hline Married & 12 & 12 & 24 \\
\hline High school diploma only & 13 & 12 & 25 \\
\hline College degree or more & 6 & 8 & 14 \\
\hline $\begin{array}{l}\text { Duration of CPP in years } \\
\text { Mean, median (range) }\end{array}$ & $6.3,4.0(0.5-22)$ & $10.5,7.3(1-31)$ & $8.4,7.0(0.5-31)$ \\
\hline \multicolumn{4}{|l|}{ Activity restriction, last 3 months } \\
\hline Days missed work & $0.9,0(0-8)$ & $0.5,0(0-5)$ & $0.8,0(0-8)$ \\
\hline Days reduced activity & $14.0,6.0(0-90)$ & $11.8,5.5(0-70)$ & $12.8,6.0(0-90)$ \\
\hline Davs staved in bed $>1 / 2$ day & $2.4,0(0-20)$ & $1.1,1.0(0-4)$ & $1.7,0.5(0-20)$ \\
\hline \multicolumn{4}{|l|}{ Depression $^{\mathrm{a}}$} \\
\hline Mean, median (range) & $7,6(0-15)$ & $4,2(0-21)$ & $5,3(0-21)$ \\
\hline \multicolumn{4}{|l|}{ Reported current symptoms } \\
\hline Low-back pain & 17 & 18 & 35 \\
\hline $\begin{array}{l}\text { Menstrual cramps (within } \\
\text { last } 6 \text { months) }\end{array}$ & 15 & 17 & 32 \\
\hline Bowel problems & 10 & 13 & 23 \\
\hline Painful intercourse & 7 & 8 & 15 \\
\hline Bladder problems & 6 & 8 & 14 \\
\hline \multicolumn{4}{|l|}{ Comorbidities ${ }^{\text {b }}$} \\
\hline Asthma & 3 & 3 & 6 \\
\hline Migraines & 0 & 3 & 3 \\
\hline Endometriosis & 2 & 1 & 3 \\
\hline Diabetes & 2 & 0 & 2 \\
\hline \multicolumn{4}{|l|}{ Reported history of occurrence } \\
\hline Laparoscopy & 7 & 8 & 15 \\
\hline Sexual/physical abuse & 3 & 7 & 10 \\
\hline Hysterectomy & 0 & 1 & 1 \\
\hline
\end{tabular}

${ }^{\text {aS }}$ core on Beck Depression Inventory, in which 0-4 indicates no or minimal, 5-7 mild, 8-15 moderate, and 16+ severe depression.

${ }^{\mathrm{b}}$ Only conditions for which patient reported taking medication.

$\mathrm{CPP}$, chronic pelvic pain.

cluded in the protocol was performed for 2 of 10 patients. Several patients at that site noted that the clinicians seemed to apply the procedures differently.

3. Application of placebo treatment procedures. Clinicians followed the prescribed protocol, except in one case, where on the first visit a clinician delivered the placebo treatment by mistake to a patient in the active group.

4. Time spent by clinician with each patient at each treatment visit was to be 15 minutes. Although recording of time spent was not consistently accomplished, it appears that time spent by clinicians with patients was not uniform across sites. At site 1 , times were not recorded, but the PC reported that he spent 10-15 minutes per visit with each patient in both treatment groups. At site 2, time with the clinician was recorded for almost all treatment visits; the clinician spent a mean of 8 minutes with patients in the placebo group and 11 minutes with patients in the active group. At site 3, time was not recorded consistently, but it appears from the data recorded that a mean of 11 minutes was spent with placebo group and 17 with active group patients.

\section{Patient compliance}

Three of the 39 patients did not complete the study (see Table 1). One, in the placebo group, dropped out after two treatments because she did not like the treatment. Another dropped out and could not be contacted. The third dropped out after the 12th visit because of other 
Table 3. Prescription and Nonprescription Medication and Supplement Use by Group

\begin{tabular}{lccc}
\hline & $\begin{array}{c}\text { Placebo group } \\
(\mathrm{n}=19)\end{array}$ & $\begin{array}{c}\text { Active group } \\
(\mathrm{n}=18)\end{array}$ & $\begin{array}{c}\text { Total } \\
(\mathrm{n}=37)\end{array}$ \\
\hline Prescription medication & & & 9 \\
$\quad$ Female hormones (including oral contraceptives) & 4 & 5 & 6 \\
$\quad$ Antidepressants/tranquilizers & 3 & 3 & 4 \\
$\quad$ Analgesic/anti-inflammatory & 2 & 7 & 12 \\
$\quad$ Medications for conditions other than CPP & 5 & 8 & 19 \\
$\quad$ None & & 12 & 21 \\
Nonprescription medication & 9 & 2 & 5 \\
$\quad$ Analgesic/anti-inflammatory & 3 & 5 & 12 \\
Medications for conditions other than CPP & 7 & & 15 \\
None & 4 & 6 & 14 \\
Supplements/herbs & 8 & 7 & 12 \\
$\quad$ For general health & 5 & 7 & \\
$\quad$ None & & & \\
for non-CPP related health problems & & & \\
\hline
\end{tabular}

$\mathrm{CPP}$, chronic pelvic pain.

health problems unrelated to the study. All 36 patients who completed the study were compliant with 14 treatment visits. However, 3 patients, 2 in the placebo group and 1 in the active group, initiated massage therapy and one of these also initiated reiki therapy during the study.

\section{Assessment of treatment effects}

Baseline scores on outcome measures. Table 4 shows the baseline scores on the outcome measures and the SF-36. For the primary outcome measure, the PDI, as well as for the MPQ and the Physical Component and Mental Component SF-36 subscales, the placebo and active groups were approximately equivalent at baseline. The active group had greater pain as measured by the VAS at baseline (median of 4.0 compared to 2.1), although this was not reflected by either the MPQ or the Bodily Pain subscale of the SF-36. There was a great deal of variability in the scores for the SF-36 (Table 4).

Changes in outcome measures. The primary assessment of treatment effects was the change in

Table 4. Baseline Scores on Outcome Measures by Groupa

\begin{tabular}{|c|c|c|}
\hline \multirow[b]{2}{*}{ Outcome measure } & \multicolumn{2}{|c|}{ Group } \\
\hline & $\begin{array}{c}\text { Placebo } \\
\mathrm{n}=19\end{array}$ & $\begin{array}{l}\text { Active } \\
\mathrm{n}=20\end{array}$ \\
\hline Pain Disability Index (PDI) & $19.0(22.0)$ & $19.5(13.5)$ \\
\hline Visual Analogue Scale (VAS) (cm) & $2.1(2.7)$ & $4.0(4.0)$ \\
\hline McGill Pain Questionnaire (MPQ) & $22.0(31.0)$ & $24.0(24.0)$ \\
\hline \multicolumn{3}{|l|}{ SF-36 subscales } \\
\hline Physical function & $80.0(20.0)$ & $80.0(20.0)$ \\
\hline Role functioning because physical problems & $50.0(75.0)$ & $62.5(100)$ \\
\hline Bodily pain & $41.0(21.0)$ & $41.0(19.0)$ \\
\hline General health & $67.0(52.0)$ & $57.0(33.5)$ \\
\hline Vitality/fatigue & $45.0(25.0)$ & $50.0(27.5)$ \\
\hline Social functioning & $75.0(37.5)$ & $62.5(37.5)$ \\
\hline Role functioning because of emotional problems & $66.7(66.7)$ & $100.0(50.0)$ \\
\hline Mental health & $60.0(32.0)$ & $76.0(16.0)$ \\
\hline Physical component score & $40.6(11.7)$ & $42.0(17.1)$ \\
\hline Mental component score & $44.9(16.3)$ & $50.8(16.0)$ \\
\hline
\end{tabular}

${ }^{a}$ Median (interquartile range). 
the PDI at week 6; the median improvement was, for the placebo and active group, respectively: 4.0 and 9.0 at site $1,8.0$ and 7.0 at site 2, and 14.0 and 1.0 at site 3 . For the PDI, VAS, and $M P Q$, the direction of differences between the active and placebo groups were inconsistent across sites (Table 5). Therefore, the results were not combined across sites and overall treatment effect sizes were not estimated.

Evaluation of doctor-patient interaction and perception of treatment group assignment. Table 6 shows patients' evaluation of the clinicians at each site by group. At all sites, all responses for interactions with the clinicians were "excellent" or "good," with evaluations of their outcomes slightly less positive.

In terms of blinding, perception of treatment group assignment in both groups was correct in half the patients $(8 / 16$ for the placebo group and $9 / 18$ in the active group), as shown in Table 7.

\section{DISCUSSION}

This was a pilot study; it was not designed to investigate the efficacy of chiropractic care for symptoms of CPP. It was designed to provide the investigators with information on whether it is feasible to move forward with plans for an RCT on that topic.

\section{Patient characteristics}

Comparing this study to our previous singlegroup study (Hawk et al., 1997), baseline PDI scores and symptomatology were similar. Antidepressant use in this study compared to the earlier one was also similar, whereas hormone use was considerably less (15\% versus $37 \%)$,

Table 5. Changes in Outcome Measures for Patients Completing Week 6 Visit, by Group and Site $(n=36)^{\mathrm{a}}$

\begin{tabular}{|c|c|c|c|c|c|c|}
\hline \multirow[b]{2}{*}{$\begin{array}{l}\text { Outcome } \\
\text { measure }\end{array}$} & \multicolumn{2}{|c|}{ Site 1} & \multicolumn{2}{|c|}{ Site 2} & \multicolumn{2}{|c|}{ Site 3} \\
\hline & $\begin{array}{c}\text { Placebo } \\
\mathrm{n}=7\end{array}$ & $\begin{array}{l}\text { Active } \\
\mathrm{n}=9\end{array}$ & $\begin{array}{c}\text { Placebo } \\
\mathrm{n}=6\end{array}$ & $\begin{array}{c}\text { Active } \\
\mathrm{n}=6\end{array}$ & $\begin{array}{c}\text { Placebo } \\
\mathrm{n}=5\end{array}$ & $\begin{array}{c}\text { Active } \\
\mathrm{n}=3\end{array}$ \\
\hline \multicolumn{7}{|l|}{ PDI } \\
\hline Baseline score & $\begin{array}{c}19.0 \\
(2,65)\end{array}$ & $\begin{array}{c}22.0 \\
(10,32)\end{array}$ & $\begin{array}{c}17.0 \\
(8,32)\end{array}$ & $\begin{array}{c}13.0 \\
(8,36)\end{array}$ & $\begin{array}{c}19.0 \\
(6,43)\end{array}$ & $\begin{array}{c}13.0 \\
(4,32)\end{array}$ \\
\hline Week 6 change $^{\mathrm{b}}$ & $\begin{array}{c}4.0 \\
(-18,32)\end{array}$ & $\begin{array}{c}9.0 \\
(1,20)\end{array}$ & $\begin{array}{c}8.0 \\
(2,15)\end{array}$ & $\begin{array}{c}7.0 \\
(-5,21)\end{array}$ & $\begin{array}{c}14.0 \\
(1,28)\end{array}$ & $\begin{array}{c}1.0 \\
(-30,22)\end{array}$ \\
\hline Week 12 change $^{c}$ & $\begin{array}{c}7.0 \\
(-10,46)\end{array}$ & $\begin{array}{c}9.0 \\
(0,27)\end{array}$ & $\begin{array}{c}10.5 \\
(0,19)\end{array}$ & $\begin{array}{c}9.5 \\
(-14,16)\end{array}$ & $\begin{array}{c}5.0 \\
(1,20) \\
(n=4)\end{array}$ & $\begin{array}{c}2.0 \\
(-39,25)\end{array}$ \\
\hline \multicolumn{7}{|l|}{ VAS (cm) } \\
\hline Baseline score & $\begin{array}{c}2.3 \\
(1.3,7.2)\end{array}$ & $\begin{array}{c}5.6 \\
(0,7.6)\end{array}$ & $\begin{array}{c}1.2 \\
(0,6.0)\end{array}$ & $\begin{array}{c}4.3 \\
(0,10.0)\end{array}$ & $\begin{array}{c}2.0 \\
(1.0,4.1)\end{array}$ & $\begin{array}{c}1.7 \\
(0.2,2.8)\end{array}$ \\
\hline Week 6 change $^{b}$ & $\begin{array}{c}1.4 \\
(-1.2,3.4)\end{array}$ & $\begin{array}{c}3.6 \\
(0,7.6)\end{array}$ & $\begin{array}{c}1.1 \\
(-0.5,6.0)\end{array}$ & $\begin{array}{c}2.0 \\
(-1.6,5.0)\end{array}$ & $\begin{array}{c}1.3 \\
(-1.7,2.8)\end{array}$ & $\begin{array}{c}-6.3 \\
(-7.0,-0.3)\end{array}$ \\
\hline Week 12 change $^{\mathrm{c}}$ & $\begin{array}{c}1.1 \\
(-2.9,3.5)\end{array}$ & $\begin{array}{c}3.6 \\
(-0.6,7.6)\end{array}$ & $\begin{array}{c}0.4 \\
(-1.4,3.8)\end{array}$ & $\begin{array}{c}2.3 \\
(-4.0,5.1)\end{array}$ & $\begin{array}{c}0.3 \\
(-3.5,3.9) \\
(n=4)\end{array}$ & $\begin{array}{c}-2.3 \\
(-4.9,0.2)\end{array}$ \\
\hline \multicolumn{7}{|l|}{ MPQ (total PRI) ${ }^{\mathrm{d}}$} \\
\hline Baseline score & $\begin{array}{c}27.0 \\
(7,54)\end{array}$ & $\begin{array}{c}23.0 \\
(12,51)\end{array}$ & $\begin{array}{c}33.5 \\
(9,51)\end{array}$ & $\begin{array}{c}10.0 \\
(8,54)\end{array}$ & $\begin{array}{c}8.0 \\
(1,32) \\
(n=5)\end{array}$ & $\begin{array}{c}24.0 \\
(14,31)\end{array}$ \\
\hline Week 6 change ${ }^{b}$ & $\begin{array}{c}3.0 \\
(-5,26)\end{array}$ & $\begin{array}{c}9.0 \\
(1,25)\end{array}$ & $\begin{array}{c}8.0 \\
(5,26) \\
(n=3)\end{array}$ & $\begin{array}{c}3.5 \\
(-14,36) \\
(n=4)\end{array}$ & $\begin{array}{c}1.0 \\
(-6,12)\end{array}$ & $\begin{array}{c}11.0 \\
(-10,17)\end{array}$ \\
\hline
\end{tabular}

${ }^{a}$ Median (minimum, maximum); positive values indicate improvement.

${ }^{\mathrm{b}}$ Change score from baseline to end of week 6 .

${ }^{\mathrm{c}}$ Change score from baseline to end of week 12 .

${ }^{\mathrm{d}} \mathrm{MPQ}$ was not administered at week 12 .

PDI, Pain Disability Index; VAS, Visual Analogue Scale; MPQ, McGill Pain Questionnaire, PRI Pain Rating Index. 
Table 6. Evaluation of Doctor-Patient Interaction by Group and Site ${ }^{a}$

\begin{tabular}{|c|c|c|c|c|c|c|c|c|}
\hline \multirow[b]{2}{*}{$\begin{array}{l}\text { Doctor } \\
\text { characteristic }\end{array}$} & \multicolumn{2}{|c|}{ Site 1} & \multicolumn{2}{|c|}{ Site 2} & \multicolumn{2}{|c|}{ Site 3} & \multicolumn{2}{|c|}{ All } \\
\hline & $\begin{array}{c}\text { Placebo } \\
\mathrm{n}=7\end{array}$ & $\begin{array}{l}\text { Active } \\
\mathrm{n}=9\end{array}$ & $\begin{array}{c}\text { Placebo } \\
\mathrm{n}=6\end{array}$ & $\begin{array}{l}\text { Active } \\
\mathrm{n}=6\end{array}$ & $\begin{array}{c}\text { Placebo } \\
\mathrm{n}=5\end{array}$ & $\begin{array}{l}\text { Active } \\
\mathrm{n}=3\end{array}$ & $\begin{array}{l}\text { Placebo } \\
\mathrm{n}=18\end{array}$ & $\begin{array}{l}\text { Active } \\
\mathrm{n}=18\end{array}$ \\
\hline Technical skills & 6 & 9 & 6 & 6 & 5 & 3 & 17 & 18 \\
\hline Time spent & 7 & 9 & 5 & 6 & 5 & 3 & 17 & 18 \\
\hline Attention & 7 & 9 & 6 & 5 & 5 & 3 & 17 & 17 \\
\hline $\begin{array}{l}\text { Outcomes } \\
\text { (how much you } \\
\text { were helped) }^{\mathrm{b}}\end{array}$ & 1 & 4 & 4 & 3 & 2 & 3 & 7 & 10 \\
\hline
\end{tabular}

aNumber of patients in each group who responded "excellent" or "very good" on "Evaluation of Clinical Services" questionnaire are provided.

$\mathrm{b}_{n}=17$ for placebo group due to missing response.

with prescription analgesic use $(10 \%$ versus $5 \%)$ and nonprescription analgesic use (54\% versus $63 \%$ ) being not too dissimilar. Baseline depression as measured by the BDI was in the mild category for this study and moderate for the previous one.

Compared to characteristics of patients in studies of medical care for women with CPP, our patients were in the same age range and were similar in terms of low-back pain and dysmenorrhea, but there appeared to be fewer with a history of sexual/physical abuse (Peters et al., 1991; Reiter, 1990; Reiter and Gambone, 1990; Reiter \& Milburn, 1992). Patients in our study did not report much use of supplements or herbs. It is possible that patients interested in CAM therapies were screened out because of the exclusion of those with recent chiropractic experience. Generally, it appears that our patients were fairly similar to those in our previous study and to medical CPP patients.

\section{Recruitment issues}

It appears that we cannot recruit enough patients for a larger study using this study's pa- rameters, particularly in respect to the eligibility criteria and screening protocols. Further study is needed on the necessity of excluding patients with recent chiropractic experience. Also, exploration of methods to expedite the screening process and develop referral relationships with local gynecologists is warranted.

\section{Delivery of standardized procedures and record keeping of procedures used}

The chiropractic clinicians followed strict protocols for delivering standardized procedures without a great deal of variation and maintained more detailed records about specific treatment procedures than are often required in clinical studies, facilitating in-depth analysis. Even though no differences were noted in patient satisfaction or perception of group assignment, patients did note differences between clinicians' treatments, usually in the case where there were large differences in the experience level of the clinicians. Because outcomes were ambiguous, it behooves us to develop better ways for future multisite studies to ensure that clinicians are actually deliv-

Table 7. Perception of Group Assignment by Group and Site for Patients Completing the Study $(n=36)$

\begin{tabular}{|c|c|c|c|c|c|c|c|c|c|}
\hline \multirow{2}{*}{$\begin{array}{l}\begin{array}{l}\text { Site } 1 \\
(\mathrm{n}=16)\end{array} \\
\text { Perception }\end{array}$} & \multicolumn{2}{|c|}{ Group } & \multirow{2}{*}{$\begin{array}{c}\begin{array}{c}\text { Site } 2 \\
(\mathrm{n}=12)\end{array} \\
\text { Perception }\end{array}$} & \multicolumn{2}{|c|}{ Group } & \multirow{2}{*}{$\begin{array}{c}\begin{array}{c}\text { Site } 3 \\
(\mathrm{n}=8)^{\mathrm{a}}\end{array} \\
\text { Perception }\end{array}$} & \multicolumn{2}{|c|}{ Group } & \multirow{2}{*}{$\frac{\begin{array}{c}\text { Total } \\
\text { correct }\end{array}}{\mathrm{a}}$} \\
\hline & $\mathrm{P}$ & A & & $\mathrm{P}$ & $\mathrm{A}$ & & $\mathrm{P}$ & A & \\
\hline Placebo & 4 & 5 & Placebo & 2 & 3 & Placebo & 2 & 1 & $8 / 16$ \\
\hline Active & 3 & 4 & Active & 4 & 3 & Active & 1 & 2 & $9 / 18$ \\
\hline
\end{tabular}

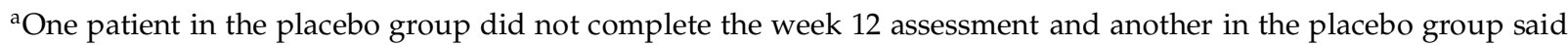
she could not guess her group status, thus 6 of 8 patients are represented.
} 
ering the same procedures in terms of biomechanical forces and techniques.

\section{Identity of the active agent}

One would expect the active group to show greater improvement than the placebo group, if the procedures used were, in fact, "active" and "placebo" agents. However, this pattern was only discernable at site 1 , where the primary clinician was the most highly experienced in this technique but also was the only one who varied the active procedure in response to individual patient needs. At site 2, patients in both groups improved approximately equally, and at site 3, it appeared that patients in the placebo group improved more, although the sample sizes were extremely small. These ambiguous results indicate a need to ensure that the active and placebo procedures are applied according to strict biomechanical parameters in a multisite study, in order to eliminate variation introduced by use of different clinicians.

\section{Success of blinding}

From patient report of satisfaction with the intervention and belief about group assignment, the placebo intervention was believable. The question that must be answered before conducting a placebo-controlled trial, however, is related to the issue of the identity of the active agent: Was the placebo intervention, in fact, a placebo? Further investigation of the biomechanical forces producing treatment effects is certainly warranted.

\section{Summary}

The technical and personnel resources required to achieve adequate standardization of procedures at multiple sites may make a placebo-controlled trial unfeasible, given our current lack of knowledge about the active agent in manual chiropractic procedures. It might be more efficient to reverse the traditional order of experimentation used for pharmaceuticals, which begins with safety, proceeds to efficacy and finally to effectiveness. Because chiropractic-a CAM profession using manual methods for more than 100 years-can scarcely be considered in the same category as a newly developed medication, it might be reasonable to first investigate effectiveness. If chiropractic care that is provided by experienced chiropractors who are allowed to use their best clinical judgment of how to apply the procedures is documented in such studies to improve patient outcomes compared to standard medical care alone, more in-depth and controlled studies would then be warranted to identify specific aspects of that gestalt of care that are most responsible for the outcomes or if there are certain subpopulations of patients who benefit most from them.

\section{ACKNOWLEDGMENTS}

This study was supported in part by National Institutes of Health Center Grant U01-AT00170 from the National Center for Complementary and Alternative Medicine. Additional funding was provided by the National Chiropractic Mutual Insurance Corporation. We would like to thank Jaeson Fournier, D.C.; James Jedlicka, D.C.; Dennis Lopez, D.C.; Rebecca Mjoen, D.C.; Chutima Phongphua, M.D., D.C.; Robert Rowell, D.C.; and Anne Spicer, D.C., for providing the highest quality of patient care, and, for their essential contributions to gathering and managing the data, Sarah Bittell, D.C.; Lori Byrd; Lance Corber; Ruth Ann Marks; Cheri Meyer; Judy McCormack; Elaine Morschhauser, D.C.; Scott Morschhauser; Erica Plaiser, M.S.; and Leah Ustas. Finally, special thanks to John Healy for his creative efforts with the recruitment campaign.

\section{REFERENCES}

Balon J, Aker PD, Crowther ER, Danielson C, Cox PG, O'Shaughnessy D, Walker C, Goldsmith CH, Duku E, Sears MRA. A comparison of active and simulated chiropractic manipulation as adjunctive treatment for childhood asthma. N Engl J Med 1998;339:1013-1020.

Beck AT, Steer RA, Garbin MG. Psychometric properties of the Beck Depression Inventory: Twenty-five years of evaluation. Clin Psychol Rev 1988;8:77-100.

Bolton JE. Research design in chiropractic. J Manipulative Physiol Ther 1999;22:483-487.

Bove G, Nilsson N. Spinal manipulation in the treatment of episodic tension-type headache: A randomized controlled trial. JAMA 1998;280:1576-1579. 
Browning JE. Chiropractic distractive decompression in the treatment of pelvic pain and organic dysfunction in patients with evidence of lower sacral nerve root compression. J Manipulative Physiol Ther 1988;11:426-432.

Browning JE. Pelvic pain and organic dysfunction in a patient with low back pain: Response to distractive manipulation: A case presentation. J Manipulative Physiol Ther 1987;10:116-121.

Browning JE. The mechanically induced pelvic pain and organic dysfunction syndrome: An often-overlooked cause of bladder, bowel, gynecologic, and sexual dysfunction. J Neuromusculoskeletal System 1996;4:52-66.

Browning JE. Uncomplicated mechanically induced pelvic pain and organic dysfunction in low back pain patients. J Can Chiro Assoc 1991;35:149-155.

Byrd L, Hawk C, Backman J, Evans R, Long CR, Morschhauser S, Morschhauser E, Phongphua C. A multisite pilot on chronic pelvic pain: The recruitment process. Proceedings of the 129th Annual Meeting of the American Public Health Association, 1999.

Chibnall JT, Tait RC. The Pain Disability Index: Factor structure and normative data. Arch Phys Med Rehabil 1994;75:1082-1086.

Coulehan JL. Chiropractic and the clinical art. Soc Sci Med 1985;21:383-390.

Field T, Ironson G, Scafidi F, Nawrocki T, Goncalves A, Burman I, Pickens J, Fox N, Schanberg S, Kuhn C. Massage therapy reduces anxiety and enhances EEG pattern of alertness and math computations. Int J Neurosci 1996;86:197-205.

Gronblad M, Hupli M, Wennerstrand P, Jarvinen E, Lukinmaa A, Kouri JP, Karaharju EO. Intercorrelation and test-retest reliability of the pain disability index (PDI) and the Oswestry disability questionnaire (ODQ) and their correlation with pain intensity in low back pain patients. Clin J Pain 1993;9:189-195.

Gronblad M, Jarvinen E, Hurri H. Relationship of the Pain Disability Index (PDI) and the Oswestry Disability Questionnaire (ODQ) with three dynamic physical tests in a group of patients with chronic low-back and leg pain. Clin J Pain 1994;10:197-203.

Haldeman S, Chapman-Smith D, Petersen DM. Guidelines for Chiropractic Quality Assurance and Practice Parameters: Proceedings of the Mercy Center Consensus Conference, Gaithersburg, MD: Aspen Publishers, 1992.

Hawk C, Long C, Azad A. Chiropractic care for women with chronic pelvic pain: A prospective single-group intervention study. J Manipulative Physiol Ther 1997; 20:73-79.

Hawk C. Chiropractic clinical research: Where are we looking for the key? J Neuromusculoskeletal System 2000;7:150-155.

Hondras MA, Long CR, Brennan P. Spinal manipulative therapy vs. a low force mimic maneuver for women with primary dysmenorrhea: A randomized, observerblinded clinical trial. Pain 1999;81:105-114.

Hrobjartsson A, Goetzsche PC. Is the placebo powerless? An analysis of clinical trials comparing placebo with no treatment. N Engl J Med 2001;344:1594-1602.

Ironson G, Field T, Scafidi F, Hashimoto M, Kumar M,
Kumar A, Price A, Goncalves A, Burman I, Tetenman C, Patarca R, Fletcher MA. Massage therapy is associated with enhancement of the immune system's cytotoxic capacity. Int J Neurosci 1996;84:205-217.

Joyce CRB. Placebo and complementary medicine. Lancet 1994;344:1279-1281.

Kaptchuk TJ. Powerful placebo: The dark side of the randomized controlled trial. Lancet 1999;351:1722-1725.

Maa S, Gauthier D, Turner M. Acupressure as an adjunct to a pulmonary rehabilitation program. J Cardiopulmonary Rehabil 1997;17:268-276.

Melzack R. The McGill pain questionnaire. In Melzack R, ed. Pain Measurement and Assessment. New York: Raven Press, 1983:41-47.

Miller MD, Ferris DG. Measurement of subjective phenomena in primary care research: The visual analogue scale. Fam Pract Res J 1993;13:15-24.

Nordstrom DCE, Konttinen YT, Solovieva S, Friman C, Santavirta S. In- and out-patient rehabilitation in rheumatoid arthritis. Scand J Rheumatol 1996;25:200-206.

Oths K. Communication in a chiropractic clinic: How a D.C. treats his patients. Cult Med Psychol 1994;18:83113.

Peters AA, vanDorst E, Jellis B, vanZuuren E, Hermans J, Trimbos JB. A randomized clinical trial to compare two different approaches in women with chronic pelvic pain. Obstet Gynecol 1991;77:740-744.

Polk JR. A new approach to pelvic pain management. Today's Chiropractic 1991;20:42-46.

Reiter RC, Gambone JC. Demographic and historic variables in women with idiopathic chronic pelvic pain. Obstet Gynecol 1990;75:3:1:428-432.

Reiter RC, Milburn A. Management of chronic pelvic pain. Postgrad Obstet Gynecol 1992;12:1-8.

Reiter RC. A profile of women with chronic pelvic pain. Clin Obstet Gynecol 1990;33:130-136.

Tait RC, Chibnall JT, Krause S. The Pain Disability Index: Psychometric properties. Pain 1990;40:171-182.

Tait RC, Pollard CA, Margolis RB, Duckro PN, Krause SJ. The Pain Disability Index: Psychometric and validity data. Arch Phys Med Rehabil 1987;68:438-441.

Vickers AJ. Methodological issues in complementary and alternative medicine research: A personal reflection on 10 years of debate in the UK. J Altern Complement Med 1996;2:515-524.

Ware JE, Snow KK, Kosinski M, Gandek B. SF-36 Health Survey: Manual and Interpretation Guide. Boston: The Health Institute, New England Medical Center, 1993. Wewers ME, Lowe NK. A critical review of Visual Analogue Scales in the measurement of clinical phenomena. Res Nurs Health 1990;13:227-236.

Address reprint requests to: Cheryl Hawk, D.C., Ph.D. Palmer Center for Chiropractic Research 741 Brady Street Davenport, IA 52803

E-mail: hawkcheryl@aol.com 